\title{
Reduced EDHF responses and connexin activity in mesenteric arteries from the insulin-resistant obese Zucker rat
}

\author{
E. J. Young • M. A. Hill • W. B. Wiehler • C. R. Triggle • \\ J. J. Reid
}

Received: 7 December 2007 / Accepted: 17 December 2007 /Published online: 7 March 2008

(C) Springer-Verlag 2008

\begin{abstract}
Aims/hypothesis The objective of this study was to examine the effect of insulin resistance on endothelium-derived hyperpolarising factor (EDHF) and small mesenteric artery endothelial function using 25-week-old insulin-resistant obese Zucker rats (OZRs) and lean littermate control rats (LZRs). The involvement of gap junctions and their connexin subunits in the EDHF relaxation response was also assessed.

Methods Mesenteric arteries were evaluated using the following assays: (1) endothelial function by pressure myography, with internal diameter recorded using video microscopy; (2) connexin protein levels by western blotting; and (3) $\mathrm{Cx}$ mRNA expression by real-time PCR.

Results Relaxations in response to acetylcholine were significantly smaller in mesenteric arteries from the OZRs than the
\end{abstract}

Electronic supplementary material The online version of this article (doi:10.1007/s00125-008-0934-y) contains supplementary material, which is available to authorised users.

E. J. Young $\cdot$ C. R. Triggle $\cdot$ J. J. Reid

School of Medical Sciences, RMIT University,

Melbourne, Victoria, Australia

M. A. Hill

School of Medical Sciences, University of New South Wales,

Sydney, NSW, Australia

W. B. Wiehler

Faculty of Medicine, University of Calgary,

Calgary, Canada

E. J. Young $(\bowtie)$

Leica Microsystems,

495 Blackburn Road,

Mt Waverley, Victoria 3149, Australia

e-mail: elisa.young@1eica-microsystems.com
LZRs, whereas there was no difference in relaxations in response to levcromakalim. Responses to acetylcholine were not altered by nitric oxide inhibitors, but were abolished by charybdotoxin in combination with apamin, which blocked the EDHF component of the response. ${ }^{40} \mathrm{Gap} 27$ significantly attenuated the response to acetylcholine in the LZRs, but had no effect in the OZRs. Connexin 40 protein and $C \times 40$ mRNA levels in mesenteric vascular homogenates were significantly smaller in the OZRs than in the LZRs, with no difference in connexin 43 or Cx43 mRNA levels.

Conclusions/interpretation These findings demonstrate that endothelial dysfunction in mesenteric arteries from the insulin-resistant OZRs can be attributed to a defect in EDHF. The results also suggest that the defective EDHF is at least partly related to an impairment of connexin 40associated gap junctions, through a decrease in connexin 40 protein and Cx40 mRNA expression in the OZRs.

Keywords Connexins · Diabetes $\cdot$ EDHF

Endothelium-derived hyperpolarising factor - Gap junctions · Insulin resistance $\cdot$ Mesenteric artery

\begin{tabular}{|c|c|}
\hline \multicolumn{2}{|c|}{ Abbreviations } \\
\hline $\mathrm{EC}_{50}$ & half maximal effective concentration \\
\hline EDHF & endothelium-derived hyperpolarising factor \\
\hline $\mathrm{K}_{\mathrm{Ca}}$ & calcium-activated potassium channel \\
\hline LZR & lean Zucker rat \\
\hline NAME & L- $N^{\omega}$-nitro-arginine methyl ester \\
\hline NO & nitric oxide \\
\hline ODQ & $1 H$-(1,2,4)oxadiazolo(4,3-a)quinoxalin-1-one \\
\hline OZR & obese Zucker rat \\
\hline STZ & streptozotocin \\
\hline TRAM-34 & $\begin{array}{l}\text { 1-[(2-chlorophenyl)diphenylmethyl]-1H- } \\
\text { pyrazole }\end{array}$ \\
\hline
\end{tabular}




\section{Introduction}

Endothelial dysfunction is a key factor in the development of vascular complications in insulin resistance and diabetes, and has largely been associated with defects in nitric oxide (NO)-derived vasodilation [1]. However, vascular complications may also be related to defects in endotheliumderived hyperpolarising factor (EDHF), which plays an important physiological role alongside NO in endotheliumderived relaxation responses, especially in small arteries and arterioles, with its importance increasing as the size of the vessel decreases $[1,2]$.

Studies using the small-conductance calcium-activated potassium $\left(\mathrm{SK}_{\mathrm{Ca}}\right)$ channel blocker apamin in combination with charybdotoxin, which blocks the intermediate-conductance $\mathrm{K}_{\mathrm{Ca}}\left(\mathrm{IK}_{\mathrm{Ca}}\right)$ channels and large-conductance $\mathrm{K}_{\mathrm{Ca}}$ channels, have indicated that the activation of $\mathrm{SK}_{\mathrm{Ca}}$ and $\mathrm{IK}_{\mathrm{Ca}}$ channels are an essential component of an EDHF-mediated response [2-4]. Furthermore, 1-[(2-chlorophenyl)diphenylmethyl]$1 H$-pyrazole (TRAM-34), a specific inhibitor of $\mathrm{IK}_{\mathrm{Ca}}$ channels, has been used in combination with apamin to confirm that $\mathrm{IK}_{\mathrm{Ca}}$ and $\mathrm{SK}_{\mathrm{Ca}}$ channels are involved in EDHFmediated vasodilation. The combination of TRAM-34 and apamin has been used to block EDHF responses in rat caudal [5], saphenous [6], middle cerebral [7] and mesenteric arteries [8] and guinea pig carotid arteries [9].

In addition to the involvement of $\mathrm{K}_{\mathrm{Ca}}$ channels, evidence exists for a role for intercellular pathways provided by gap junctions [10-12]. Gap junctions are formed by the docking of two connexin subunits, each made up of six connexin proteins arranged around a central core [13], which creates a channel allowing the direct exchange of ions and lowmolecular-weight molecules [13]. Conduction studies have indicated that gap junctions between endothelial cells may be involved in the propagation of the EDHF response downstream along the vessel [14, 15], and EDHF-attributed hyperpolarisations also propagate from endothelial cells through the entire smooth muscle layer via gap junctions, with a current that spreads with negligible attenuation [16].

There have been few studies investigating the effect of insulin resistance and type 2 diabetes on EDHF. Studies using insulin-resistant fructose-fed rats have suggested an association between impaired endothelium-dependent relaxation and a defect in EDHF-mediated relaxations in coronary [17] and small mesenteric [18] arteries. Furthermore, the EDHF component of acetylcholine-induced relaxation was impaired in epineurial arterioles [19] and small mesenteric arteries [20] from Zucker fatty rats, a model of type 2 diabetes. EDHF-mediated responses have also been shown to be reduced in mesenteric arteries from aged Otsuka Long-Evans Tokushima fatty rats, another model of type 2 diabetes [21].

It is possible that this attenuation of EDHF function may be linked to defects in gap junctions involved in the dissemination of EDHF-invoked relaxations. Cell cultures exposed to high glucose levels have been used to study gap junctions and specific connexins in isolation, with results showing attenuation of gap junction activity in bovine aortic endothelial and smooth muscle cells [22, 23]. Furthermore, investigations using animal models of type 1 diabetes have shown attenuation of EDHF-mediated responses [24] and gap junction activity in mesenteric [25] arteries from streptozotocin (STZ)-induced diabetic rats. To our knowledge, no studies in insulin-resistant or type 2 diabetic animal models have studied changes in gap junction and connexin activity.

The present study was designed to investigate the effect of insulin resistance on EDHF-mediated endothelial function in the small mesenteric artery of the obese Zucker rat (OZR), a well established model of insulin resistance at 25 weeks of age [26], with particular focus on changes in gap junctions and associated connexins.

\section{Methods}

Animals Female 25-week-old OZRs and age-matched control lean Zucker rats (LZRs) (Monash Animal Services, Melbourne, VIC, Australia). Female rats were used because of the unavailability of male Zucker rats, and menstrual cycles were not monitored. All procedures involved were approved by the Animal Experimentation Ethics Committee of RMIT University and conformed to the Australian National Health and Medical Research Council code of practice for the care and use of animals for scientific purposes. The weight and blood glucose levels of rats were measured prior to culling. Rats were asphyxiated by $\mathrm{CO}_{2}$ inhalation, followed by decapitation, at which point blood flowing from the neck was collected. The mesenteric bed was removed and placed in Krebs solution $(111 \mathrm{mmol} / \mathrm{l} \mathrm{NaCl}, 11.5 \mathrm{mmol} / \mathrm{l}$ glucose, $10 \mathrm{mmol} / 1 \mathrm{HEPES}, 25.7 \mathrm{mmol} / 1 \mathrm{NaHCO}_{3}, 1.2 \mathrm{~mol} / 1 \mathrm{MgSO}_{4}$, $2 \mathrm{mmol} / \mathrm{l} \mathrm{CaCl}, 1.2 \mathrm{mmol} / 1 \mathrm{KH}_{2} \mathrm{PO}_{4}, 4.9 \mathrm{mmol} / \mathrm{l} \mathrm{KCl}$, $\mathrm{pH} 7.4$, at $37^{\circ} \mathrm{C}$ ), which was gassed with $95 \% \mathrm{CO}_{2}, 5 \% \mathrm{~N}_{2}$.

Pressure myography The pressure myograph technique used was based on the methodology for isolated and cannulated arterioles, as used for a number of tissues $[27,28]$. Briefly, a section of the mesenteric bed was pinned flat in a cooled $\left(4^{\circ} \mathrm{C}\right)$ chamber containing dissection buffer (3 mmol/l 3-[N-morpholino]propanesulfonic acid, $1 \mathrm{mmol} / 1 \mathrm{NaH}_{2} \mathrm{PO}_{4}, 5 \mathrm{mmol} / 1$ glucose, $2 \mathrm{mmol} / \mathrm{l}$ pyruvate, $0.02 \mathrm{mmol} / 1 \mathrm{EDTA}, 145 \mathrm{mmol} / \mathrm{l} \mathrm{NaCl}$, $5 \mathrm{mmol} / \mathrm{l} \mathrm{KCl}, 2.5 \mathrm{mmol} / 1 \mathrm{CaCl}_{2}, 1 \mathrm{mmol} / 1 \mathrm{MgSO}_{4}, 1 \%$ (wt/vol.) BSA, pH 7.4) [29]. A third-order mesenteric artery was isolated and mounted between two glass cannulas (tip diameter approximately $50 \mu \mathrm{m}$ ) in a $5 \mathrm{ml}$ chamber. The chamber was superfused with Krebs 
solution at $37^{\circ} \mathrm{C}$, at a rate of $4 \mathrm{ml} / \mathrm{min}$, and the vessel was pressurised to $80 \mathrm{mmHg}$ over $60 \mathrm{~min}$. Vessel length was adjusted as previously described [30]. Pressure and intraluminal diameter measurements were recorded on a MacLab system (MacLab/4 Chart Software, model MKIIII; AD Instruments, Sydney, NSW, Australia). Vessels with myogenic (i.e. pressure-dependent) tone between $40 \%$ and $60 \%$ relative to the maximal diameter were considered viable for experimentation.

All responses were obtained in the presence of $10 \mu \mathrm{mol} / 1$ indomethacin to block prostanoid production. Endothelial function was determined by studying responses to the endothelium-dependent dilator acetylcholine $(1 \mathrm{nmol} / 1$ to $3 \mu \mathrm{mol} / \mathrm{l})$ and the endothelium-independent dilator levcromakalim $(10 \mathrm{nmol} / \mathrm{l}$ to $10 \mu \mathrm{mol} / \mathrm{l})$. Concentration-response curves were obtained by the cumulative addition of the drug directly into the chamber. Time-control experiments $(n=4)$ demonstrated that responses to the alternating addition acetylcholine and levcromakalim did not change, in terms of half maximal effective concentration $\left(\mathrm{EC}_{50} ; p<0.05\right.$, Student's $t$ test) or maximum responses ( $p<0.05$, Student's $t$ test), when six concentration-response curves were obtained in the same mesenteric artery preparation without addition of inhibitor drugs. Therefore, a total of four to six concentration-response curves to acetylcholine and/or levcromakalim were obtained in the same preparation.

Specific inhibitors were added to the chamber 20$30 \mathrm{~min}$ before, and remained present during, the concentration-response curve to acetylcholine or levcromakalim. A 20 min washout period followed each curve, before the addition of the inhibitor. The contribution of NO to the vasodilator response was examined by incubation with L$N^{\omega}$-nitro-arginine methyl ester (NAME, $100 \mu \mathrm{mol} / \mathrm{l}$ ) and $1 H$ - $(1,2,4)$ oxadiazolo(4,3-a)quinoxalin-1-one (ODQ, $1 \mu \mathrm{mol} / \mathrm{l})$. The EDHF component was investigated using either charybdotoxin $(0.1 \mu \mathrm{mol} / \mathrm{l})$ plus apamin $(1 \mu \mathrm{mol} / \mathrm{l})$, or TRAM-34 $(1 \mu \mathrm{mol} / \mathrm{l})$ plus apamin $(1 \mu \mathrm{mol} / \mathrm{l})$. The charybdotoxin and apamin combination was assessed in the presence and absence of the NO inhibitors, whilst the apamin and TRAM-34 combination was only studied in the absence of the NO inhibitors.

The contribution of gap junctions associated specifically with connexins 40 and 43 were studied using ${ }^{40}$ Gap27

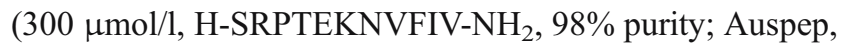
Melbourne, VIC, Australia) and ${ }^{43} \mathrm{Gap} 26(300 \mu \mathrm{mol} / \mathrm{l}$, HVCYDKSFPISHVR-NH ${ }_{2}, 97 \%$ purity; Auspep). ${ }^{37,43}$ Gap27 (300 $\mu \mathrm{mol} / 1$, H-SRPTEKTIFII-NH ${ }_{2}, 97 \%$ purity; Auspep) was also used to assess the contribution of connexin 37. ${ }^{40} \mathrm{Gap} 27$ caused the vessels to lose tone, and so the vessels were preconstricted with phenylephrine $(0.1-0.3 \mu \mathrm{mol} / \mathrm{l})$ to a level similar to the tone achieved at the beginning of the experiment; ${ }^{43} \mathrm{Gap} 26$ and ${ }^{37,43} \mathrm{Gap} 27$ did not affect myogenic tone.
At the end of all experiments, the arterioles were superfused with calcium-free Krebs buffer for $20 \mathrm{~min}$, and the maximal passive diameter was measured and recorded.

Western blotting Isolated mesenteric arteries (first-, second- and third-order arteries), weighing $\sim 150 \mathrm{mg}$, were finely minced with scissors prior to manual homogenisation for $5 \mathrm{~min}$ in lysis buffer $(150 \mu \mathrm{l}$ per $50 \mathrm{mg}$ tissue; $1 \mathrm{mmol} / 1 \mathrm{NaHCO}_{3}, 10 \mathrm{mmol} / 1 \mathrm{EDTA}, 10 \mathrm{mmol} / \mathrm{l}$ iodoacetamide, $10 \mathrm{mmol} / 1$ sodium pyrophosphate, $1 \mathrm{mmol} / \mathrm{l}$ phenylmethylsulfonyl fluoride, $1 \mathrm{U} / \mathrm{ml}$ aprotinin, $20 \mu \mathrm{mol} / \mathrm{l}$ pepstatin A, $20 \mu \mathrm{mol} / 1$ leupeptin). The homogenates were then vortexed for $2 \mathrm{~min}$ and sonicated for $5 \mathrm{~min}$, before centrifugation at $3,000 \times \mathrm{g}$ for $10 \mathrm{~min}$ at $4^{\circ} \mathrm{C}$. To account for any differences in tissue mass between LZRs and OZRs, the protein concentration of each homogenate was determined using the Bio-Rad protein assay based on the Bradford assay (Bio-Rad, Sydney, NSW, Australia), allowing equal amounts of protein from each homogenate to be analysed.

Samples containing the same amount of protein (connexins 37 and 43, $20 \mu \mathrm{g}$; connexin 40,60 $\mu \mathrm{g}$ ) were separated by electrophoresis through $10 \%$ SDS-PAGE gels ( $200 \mathrm{mV}, 30 \mathrm{~min}$ ), and transferred onto nitrocellulose paper (400 mA, 2 h). Nitrocellulose membranes were blocked with blocking buffer $(5 \%$ skimmed milk and $0.1 \%$ Tween20 in Tris-buffered saline, comprising $20 \mathrm{mmol} / \mathrm{l}$ Tris base, $137 \mathrm{mmol} / \mathrm{l} \mathrm{NaCl}$ and $1 \mathrm{~mol} / \mathrm{l} \mathrm{HCl}$ ) for $5 \mathrm{~h}$ at room temperature, to block non-specific binding sites. This was followed by overnight incubation with connexin 37 (ADI, USA), connexin 40 (ADI, USA) or connexin 43 (Transduction Laboratories, Sydney, NSW, Australia) primary antibody diluted 1:2,500 in blocking buffer at room temperature. The secondary antibodies (connexin 37 and 40: swine anti-rabbit IgG, $10 \mu \mathrm{g} / \mathrm{ml}$; connexin 43: rabbit antimouse IgG, $10 \mu \mathrm{g} / \mathrm{ml}$; all from Dako Australia, Sydney, NSW, Australia) were used diluted 1:5,000 in Tris-buffered saline and incubated for $1 \mathrm{~h}$ at room temperature. Protein levels were detected by enhanced chemiluminescence (Lumi-light Western Blotting Substrates; Roche Australia, Melbourne, VIC, Australia) and were quantified by analysis of band area and band intensity using the Bio-Rad ChemiDoc XRS system (Bio-Rad) for connexin 37, and Scion Imaging (Scion Corporation, Frederick, MD, USA) for connexins 40 and 43.

Real-time PCR Mesenteric arteries (first-, second- and third-order arteries) collected from each rat were cleaned and placed in RNase- and DNase-free collection tubes. Total RNA was subsequently extracted using an RNeasy Mini kit with DNase treatment (Qiagen, Melbourne, VIC, Australia) and first-strand cDNA was synthesised using the Sensiscript RT kit (Qiagen) with an oligo d(T) primer (Invitrogen, Melbourne, VIC, Australia). To optimise 
reaction specificity, real-time PCR was performed on each primer set using SYBR-Green (Qiagen) and a range of annealing temperatures $\left(52^{\circ} \mathrm{C}-62^{\circ} \mathrm{C}\right)$. Based on melt curve analysis, $1 \mu \mathrm{l}$ of each reaction product was placed on a DNA 500 lab chip and examined using an Agilent Technologies 2100 Bioanalyzer (Melbourne, VIC, Australia). A separate aliquot of reaction product was electrophoresed through a $1.5 \%$ (wt/vol.) agarose gel, extracted using a gel extraction kit (Qiagen), and subsequently sequenced to confirm product identity. Having ascertained an ideal annealing temperature, real-time PCR reaction efficiency was determined for all primer sets by using serial dilutions of cDNA as a template. The optimal real-time PCR reaction consisted of a hot start $\left(95^{\circ} \mathrm{C}\right.$ for $\left.15 \mathrm{~min}\right)$ followed by 40 cycles of $94^{\circ} \mathrm{C}$ for $15 \mathrm{~s}, 60.1^{\circ} \mathrm{C}$ for $30 \mathrm{~s}$ and $72^{\circ} \mathrm{C}$ for $30 \mathrm{~s}$, and optical data were collected during the extension phase. A melt curve analysis was performed on each reaction and the threshold cycle was determined using software provided with the Bio-Rad iCycler. Forward and reverse primer sequences and reaction efficiencies at an annealing temperature of $60.1^{\circ} \mathrm{C}$ for all messages are shown in Electronic supplementary material Table 1.

Drugs All drugs were purchased from Sigma Chemicals (Sydney, NSW, Australia) unless otherwise stated. All drugs were dissolved in distilled water, with the exceptions of indomethacin, which was dissolved in $0.1 \mu \mathrm{mol} / 1 \mathrm{Na}_{2} \mathrm{CO}_{3}$, levcromakalim, which was dissolved in $70 \%$ ethanol, and the gap peptides, which were dissolved in $100 \%$ dimethylsulfoxide to give stock solutions of $0.01,0.01$ and $0.3 \mathrm{~mol} / \mathrm{l}$, respectively. All stock solutions were diluted on the day of the experiment using Krebs solution.

Statistics Changes in intraluminal diameter $(\mu \mathrm{m})$ in response to acetylcholine or levcromakalim are expressed as a percentage of the maximal dilation, which was determined in the presence of calcium-free Krebs solution. Data are given as means \pm SEM. Concentration-response curves were compared using repeated-measures ANOVA. Additionally, $\mathrm{EC}_{50}$ and maximal responses were compared by unpaired Student's $t$ test. Connexin protein levels are expressed as a mean area or intensity of the band $\pm \mathrm{SEM}$, and were compared using an unpaired Student's $t$ test. Cx mRNA levels are expressed as means \pm SEM, relative to the level of $\beta$-actin $\mathrm{mRNA}(\times 0.0001)$, and were compared by unpaired Student's $t$ test. A $p$ value of less than 0.05 was considered statistically significant.

\section{Results}

Weight and glucose levels The average body weight of the OZRs $(400 \pm 3.9 \mathrm{~g}, n=21)$ was approximately double that of the lean littermate controls $(225 \pm 2.5 \mathrm{~g}, n=21 ; p<0.05$,
Student's $t$ test). Non-fasting blood glucose levels were found to be significantly ( $p<0.05$, Student's $t$ test) higher in the OZRs $(5.9 \pm 0.2 \mathrm{mmol} / \mathrm{l}, n=21)$ than the LZRs $(4.7 \pm$ $0.2 \mathrm{mmol} / \mathrm{l}, n=21)$.

Pressure myography All results have been normalised against the maximal (passive) diameter (LZR: $143 \pm 11 \mu \mathrm{m}$, $n=14$; OZR: $141 \pm 10 \mu \mathrm{m}, n=18)$. There was no significant difference ( $p>0.05$, Student's $t$ test) in the absolute active diameters (LZR, $81 \pm 9 \mu \mathrm{m}, n=14$; OZR, $71 \pm 6 \mu \mathrm{m}, n=18$ ), or in the myogenic tone achieved by mesenteric arteries from the LZR ( $53.9 \pm 3.0 \%$ of maximal diameter, $n=14)$ and OZR ( $49.6 \pm 0.4 \%$ of maximal diameter, $n=18)$.

Representative traces showing responses to acetylcholine and levcromakalim are shown in Fig. 1. The concentrationresponse curve to acetylcholine for the OZRs $\left(\mathrm{EC}_{50}\right.$ $86.0 \mathrm{nmol} / 1,95 \%$ CI $62.8-117.8 \mathrm{nmol} / 1, n=18)$ showed a significant $(p<0.05$, Student's $t$ test) 2.5 -fold rightward parallel shift compared with that for the LZRs $\left(E_{50}\right.$ $33.8 \mathrm{nmol} / 1,95 \%$ CI $23.5-48.8 \mathrm{nmol} / 1, n=14)$. There was no significant difference $(p>0.05)$ in the maximal dilation caused by acetylcholine between the LZRs $(96.6 \pm 0.7 \%$ of maximal diameter, $n=14)$ and OZRs $(95.0 \pm 1.4 \%$ of maximal diameter, $n=18$; Fig. 2a). Relaxation responses to levcromakalim were not altered in mesenteric arteries from the OZRs relative to those from the LZRs (Fig. 2b).

Responses to acetylcholine were not changed $(p>0.05$, ANOVA) by NAME plus ODQ (Fig. $3 \mathrm{a} ; n=6-7$ ) in the OZRs $(n=6-7)$ or LZRs $(n=6-7)$, but were abolished $(p<$ 0.05 , ANOVA) by a combination of TRAM-34 and apamin (Fig. 3c;n=3). Responses to levcromakalim were not altered ( $p>0.05$, ANOVA) in the presence of NAME plus ODQ (Fig. 3b; $n=3-4)$, nor were they altered $(p>0.05$, ANOVA) by incubation with TRAM-34 plus apamin (Fig. 3d; $n=3$ ). Apamin in combination with charybdotoxin abolished responses to acetylcholine in the absence of $\mathrm{NO}$ inhibitors (data not shown).

${ }^{40} \mathrm{Gap} 27(300 \mu \mathrm{mol} / \mathrm{l})$ abolished myogenic tone in both lean and obese Zucker rat preparations, and so vessels were preconstricted with phenylephrine $(0.1-0.3 \mu \mathrm{mol} / \mathrm{l})$ to achieve a level of tone similar to that observed in the absence of ${ }^{40} \mathrm{Gap} 27$. The maximal response to acetylcholine was significantly attenuated $(p<0.05$, Student's $t$ test) by $54 \%$ in the presence of $300 \mu \mathrm{mol} /{ }^{40} \mathrm{Gap} 27$ in the LZRs (Fig. $4 \mathrm{a} ; n=5$ ), but was not changed in the OZRs (Fig. 4b; $n=5$ ). Responses to levcromakalim were not altered by $300 \mu \mathrm{mol} / 1{ }^{40} \mathrm{Gap} 27$ (Fig. $4 \mathrm{c}, \mathrm{d} ; n=3$ ) in either the LZR or OZR preparations. Incubation with ${ }^{43} \mathrm{Gap} 26$ or ${ }^{37,43} \mathrm{Gap} 27$ had no effect on responses to acetylcholine or levcromakalim in the LZR or OZR third-order mesenteric arteries (data not shown).

Western blotting Comparison of western blot band intensity and area values (Fig. 5) indicated a significant $(p<0.05$, 
Fig. 1 Representative traces showing responses to acetylcholine (a, c) and levcromaka$\lim (\mathbf{b}, \mathbf{d})$ in lean Zucker rat $(\mathbf{a}$, b) and obese Zucker rat (c, d) pressurised third-order mesenteric arteries. The numbers listed above the traces represent the concentration of acetylcholine or levcromakalim administered in $\mathrm{mmol} / \mathrm{l}$

\section{a}

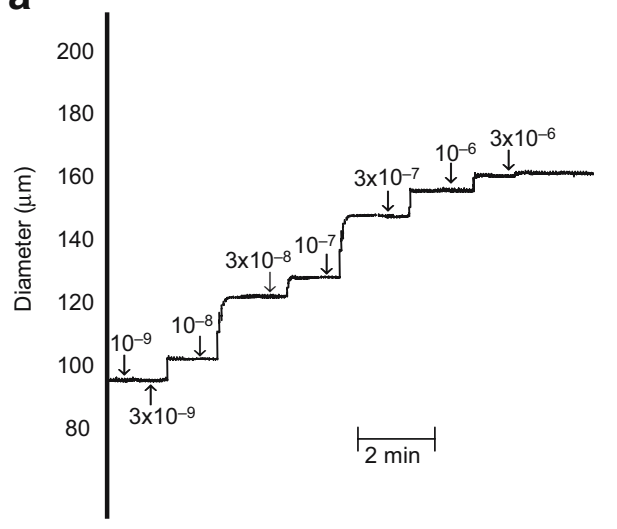

C

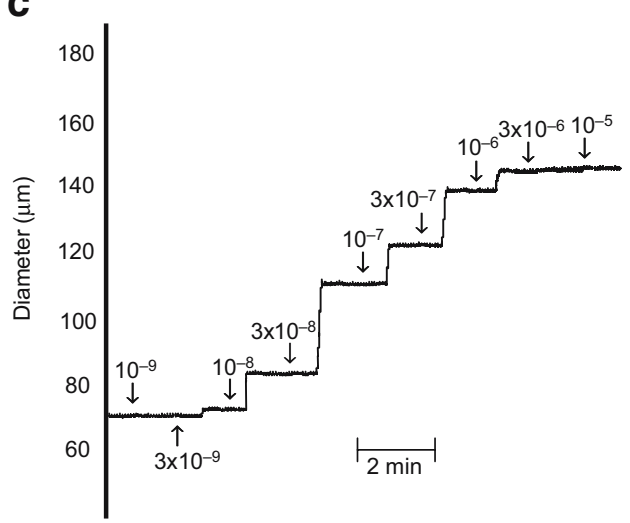

b

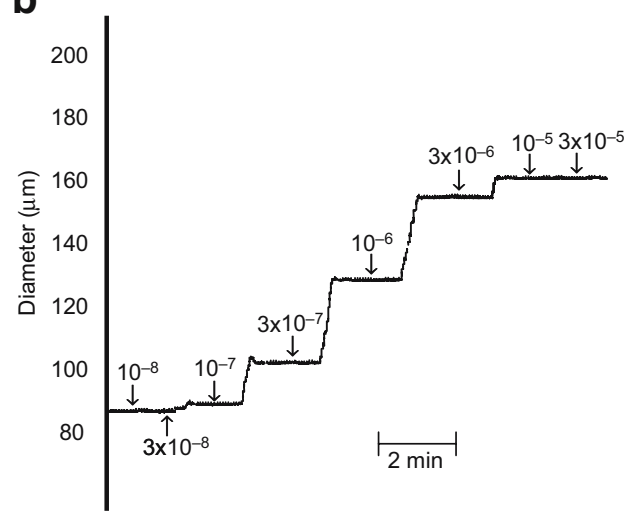

d

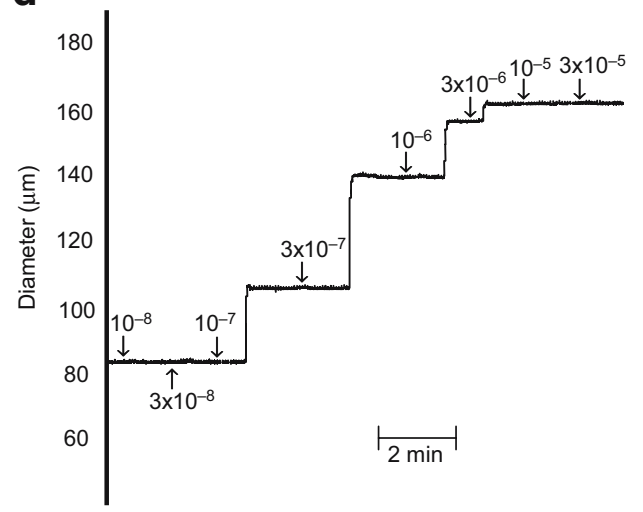

Student's $t$ test) decrease in connexin 40 protein levels in mesenteric vascular homogenates obtained from the OZRs $(n=8)$ compared with the LZRs $(n=8)$. Similarly, connexin 37 band intensity and area values were significantly smaller $(p<0.05$, Student's $t$ test) in the OZRs than in the LZRs. In contrast, there was no difference ( $p>0.05$, Student's $t$ test) in connexin 43 band area or intensity between LZRs $(n=8)$ and OZRs $(n=8)$.

Real-time PCR Quantitative analysis of Cx mRNA levels (Fig. 6) showed a significant ( $p<0.05$, Student's $t$ test) $78 \%$ decrease in expression of the gene encoding connexin 40 (Cx40, also known as Gja5) in mesenteric arteries from the OZRs $(n=6)$ compared with the LZRs $(n=7)$, and a $68 \%$ decrease in $C x 37$ (also known as Gja4) expression in the OZRs $(n=6)$ compared with the LZRs $(n=5)$. There was no change in $C x 43$ (also known as Gjal) or Cx45 (also known as Gja7) mRNA expression, the levels of both of which were low $(n=4-6)$.

\section{Discussion}

The findings from this study demonstrate that there is a decrease in the EDHF-mediated relaxation responses to acetylcholine in third-order mesenteric arteries from the 25-week-old OZRs, compared with those from lean littermate control rats. As responses to the endotheliumindependent dilator levcromakalim were not altered, this attenuation can be identified as an endothelial dysfunction, a well-established complication in animal models of insulin resistance and diabetes [1]. While there is evidence to show that the endothelium can modulate the sensitivity and maximal response to levcromakalim [31], the responses to levcromakalim were not different in the LZRs and OZRs, suggesting that any effect the endothelium has on the responses to levcromakalim is not significant.

The pressure myography results demonstrate that EDHF is the predominant endothelium-dependent vasodilator present in third-order mesenteric arteries from both the LZRs and OZRs under the experimental conditions studied (in the presence of indomethacin), since responses to acetylcholine were not affected by NO inhibitors but were abolished by a combination of charybdotoxin and apamin (in either the presence or absence of NO inhibitors) or the combination of TRAM-34 and apamin. While the 2030 min incubation time is substantially shorter than the incubation times used by other research groups [2], this incubation time has been used in our laboratory to abolish EDHF responses in third-order mesenteric arteries of the 

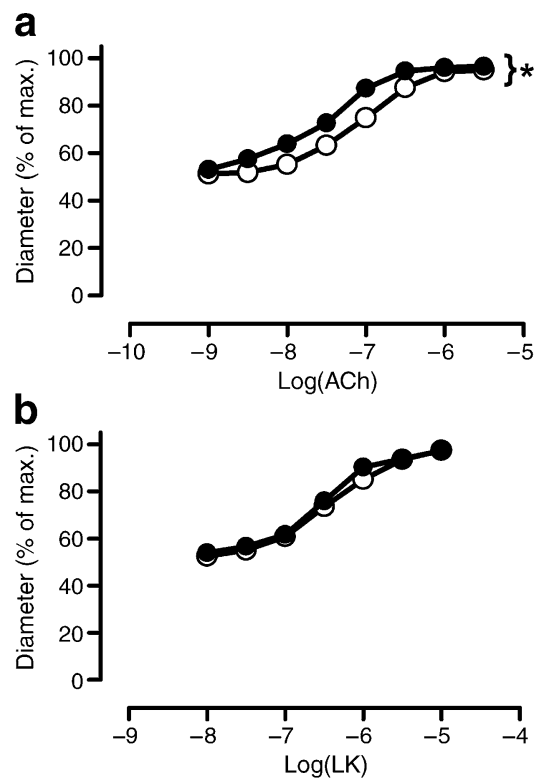

Fig. 2 Concentration-response curves for relaxations to acetylcholine (ACh) (a) and levcromakalim (LK) (b) in pressurised third-order mesenteric arteries from lean (black circles, $n=11-14$ ) and obese (white circles, $n=12-18$ ) Zucker rats, in the presence of indomethacin $(10 \mu \mathrm{mol} / \mathrm{l})$. Data points are means \pm SEM, and the values on the $x$ axes are logarithmically transformed values of concentration in $\mathrm{mol} / \mathrm{l}$. Note that error bars are smaller than the size of the symbols. ${ }^{*} p<0.05$, ANOVA. max., maximum

same diameter from Sprague-Dawley rats, whereas longer incubation times are required for other tissues such as the gracilis artery. This finding is consistent with the report of Coppey et al. [19], who demonstrated impaired EDHFmediated responses to acetylcholine in epineurial arterioles from the Zucker diabetic fatty rat. Studies using insulinresistant fructose-fed rats have also shown that EDHF function is attenuated in mesenteric [32] and coronary [17] arteries. Apamin and charybdotoxin caused significant and similar basal constriction in both LZR and OZR preparations, presumably because charybdotoxin has an inhibitory effect on large-conductance $\mathrm{K}_{\mathrm{Ca}}$ channels, which are known to be involved in the regulation of myogenic tone [33]. This is supported by experimental results showing that a combination of apamin and TRAM-34 [34] causes no change in myogenic tone in the mesenteric artery.

The present study showed that EDHF responses to acetylcholine were significantly attenuated by ${ }^{40} \mathrm{Gap} 27$ in mesenteric arteries from the LZRs, with no effect in arteries from the OZRs. ${ }^{43}$ Gap26 and ${ }^{37,43}$ Gap27 had no effect in mesenteric arteries from either LZRs or OZRs. These results suggest that gap junctions associated with connexin 40 are involved in the EDHF response in the third-order mesenteric arteries from the LZR, but do not play a role in mesenteric arteries from the OZR. Connexins 37 and 43 do not appear to play a role in EDHF-mediated vasodilation in either the LZR or the OZR third-order mesenteric artery. It should be noted that the effect of non-selective gap junction inhibitors such as $18 \alpha$-glycyrrhetinic acid and carbenoxolone were also tested for their effect on EDHF-mediated responses; however, responses to $18 \alpha$-glycyrrhetinic acid were very inconsistent, and carbenoxolone resulted in potent vasodilation, consistent with previous findings [37]. It is important to recognise that responses to ${ }^{40} \mathrm{Gap} 27$ were obtained in the presence of phenylephrine, which has been demonstrated to increase the gap junction component of an EDHF response, whilst decreasing any contribution made by endothelium-derived potassium to the EDHF response [35]. To study this effect in the absence of the ${ }^{40} \mathrm{Gap} 27$, it would be beneficial to obtain control concentration-
Fig. 3 Concentration-response curves for relaxations to acetylcholine (ACh) (a, c) and levcromakalim (LK) (b, d) in pressurised third-order mesenteric arteries from lean (black symbols, $n=3-7$ ) and obese (white symbols, $n=3-7$ ) Zucker rats before (circles) and after treatment with NAME (100 $\mu \mathrm{mol} / \mathrm{l})$ and ODQ ( $1 \mu \mathrm{mol} / 1$; upright triangles) (a, b) or treatment with TRAM$34(1 \mu \mathrm{mol} / \mathrm{l})$ plus apamin ( $1 \mu \mathrm{mol} / 1$; inverted triangles) (c, d). Data points are means \pm SEM, and the values on the $x$ axes are logarithmically transformed values of concentration in $\mathrm{mol} / \mathrm{l}$. Note that in some instances error bars are smaller than the size of the symbols. max., maximum
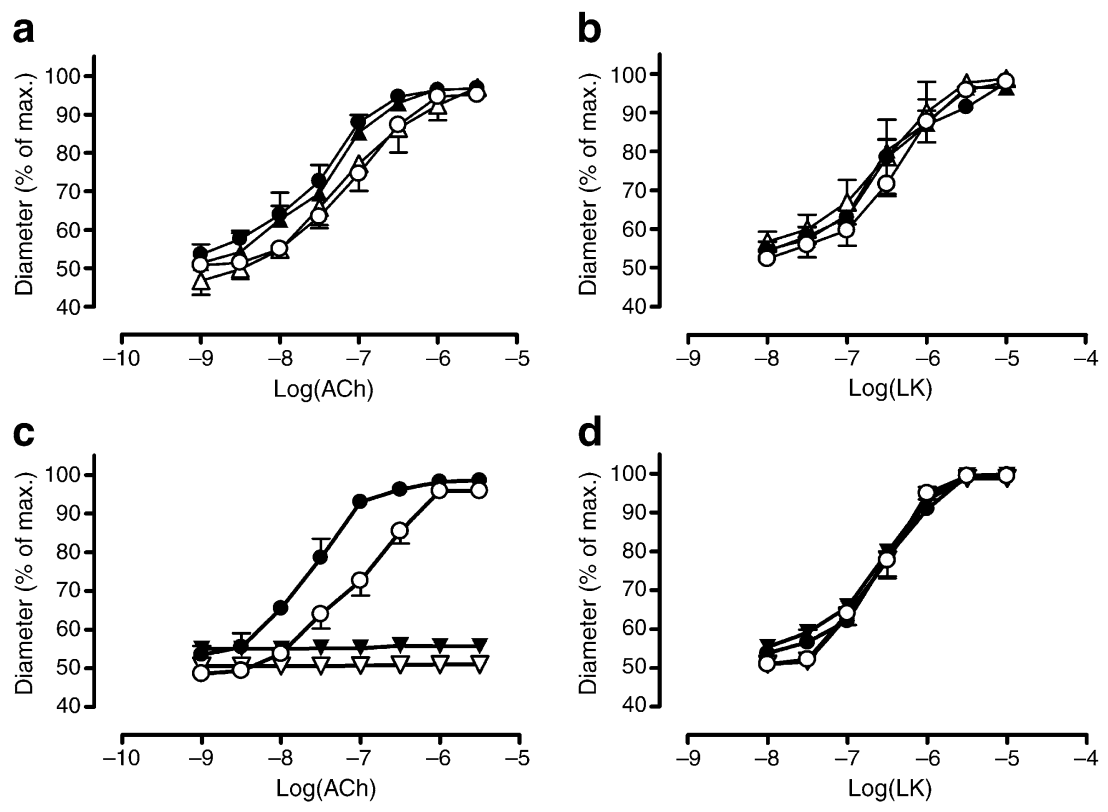
Fig. 4 Concentration-response curves for relaxations to acetylcholine $(\mathrm{ACh})(\mathbf{a}, \mathbf{b})$ and levcromakalim $(\mathrm{LK})(\mathbf{c}, \mathbf{d})$ in third-order mesenteric arteries from lean Zucker rats (black symbols, $n=3-5)$ (a, c) and obese Zucker rats (white symbols, $n=3-5)(\mathbf{b}, \mathbf{d})$ before (circles) and after (diamonds) treatment with ${ }^{40} \mathrm{Gap} 27$

$(300 \mu \mathrm{mol} / \mathrm{l})$ in the presence of $10 \mu \mathrm{mol} / 1$ indomethacin. Data points are means $\pm \mathrm{SEM}$, and the values on the $x$-axes are logarithmically transformed values of concentration in mol/l. Note that in some instances error bars are smaller than the size of the symbols. ${ }^{*} p<0.05$ ANOVA. max., maximum a

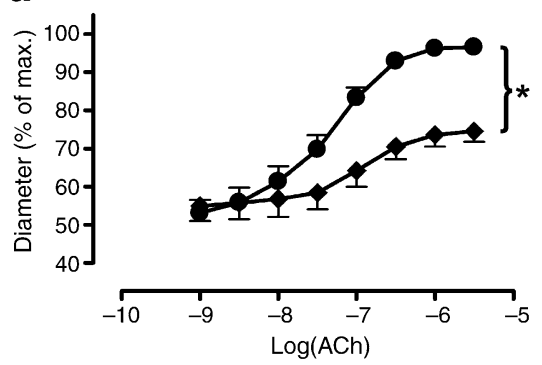

C

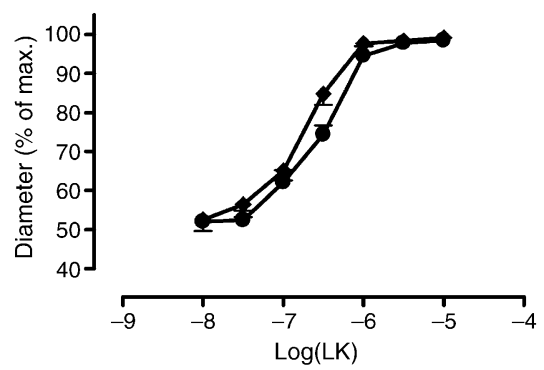

b

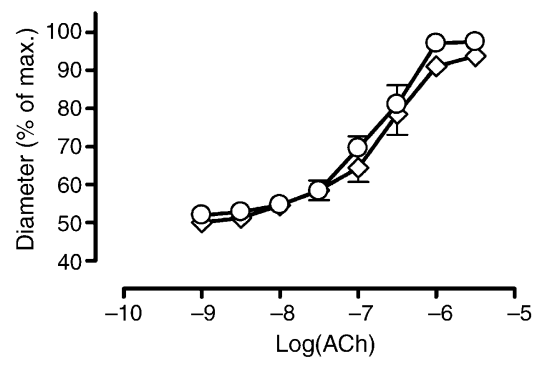

d

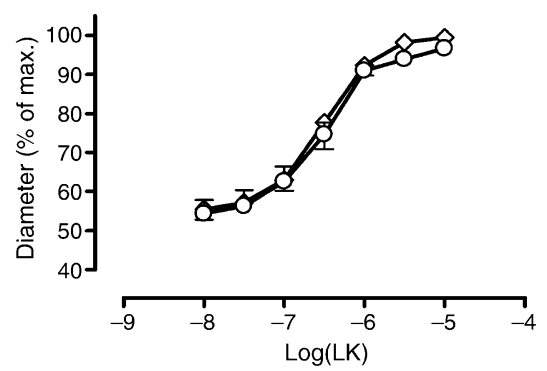

response curves to acetylcholine in the presence of phenylephrine. However, given that the phenylephrine did not have an inhibitory effect on the OZR preparations, it could be suggested that the phenylephrine concentrations used were not sufficient to inhibit any endothelium-derived potassium contribution to the EDHF response. Furthermore, phenylephrine changes myocyte intracellular calcium levels, which may in turn potentially modify endothelial cell calcium levels, and so the relative contributions of $\mathrm{NO}$ and EDHF to the response elicited by a vasodilator may be altered. To confirm that the responses to the gap peptides, in the presence of phenylephrine, are caused by EDHF, it would be beneficial to confirm that the responses can be blocked by TRAM-34 in combination with apamin.

It should also be noted that the HEPES-buffered Krebs solution may have had an inhibitory effect on the gap junctions [36], and if there were a small remaining gap junction contribution to the EDHF response in the OZRs, this may have been inhibited.

A decrease in connexin 40 protein levels and $C \times 40$ mRNA expression was also demonstrated, supporting our observation of decreased connexin 40-related relaxation in a
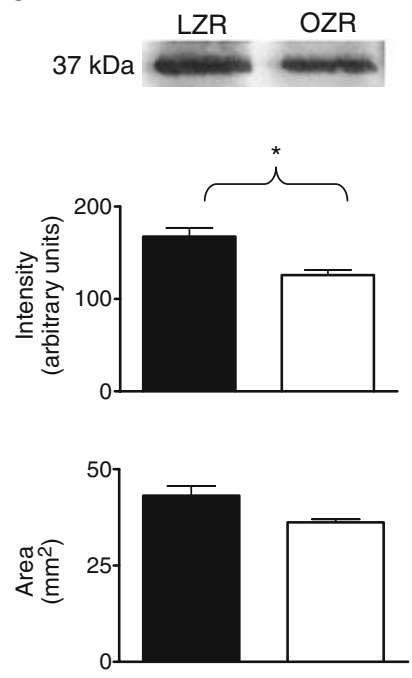

b
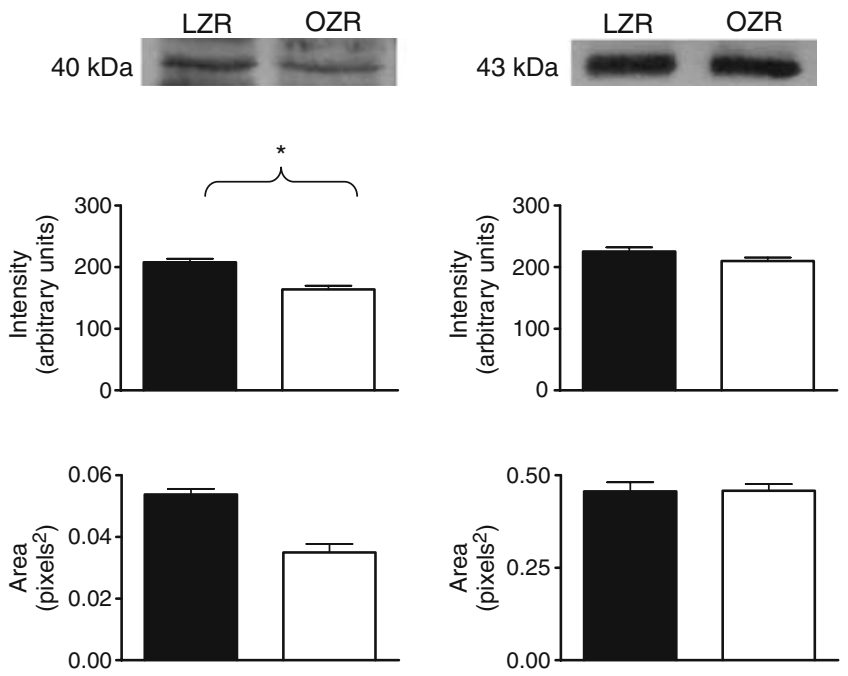

Fig. 5 Levels of connexin 37 (a) connexin 40 (b) and connexin 43 (c) in mesenteric artery homogenates from obese and lean Zucker rats. Typical western blots from lean (left band) and obese (right band) rats are shown. Western blot intensity and area are shown as means \pm SEM $(n=8)$ for lean Zucker rats (black bars) and obese Zucker rats (white bars). Connexin 37 blots were analysed using Bio-Rad Chemidoc XRS, whereas connexin 40 and connexin 43 blots were analysed using Scion imaging. ${ }^{*} p<0.05$, Student's $t$ test 


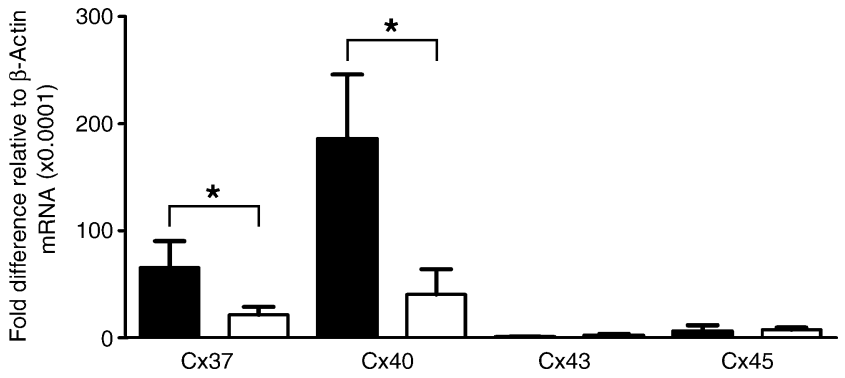

Fig. 6 Comparison of $\mathrm{Cx}$ mRNA expression of mesenteric arteries from lean (black bars) and obese (white bars) Zucker rats. Levels are expressed relative to $\beta$-actin mRNA $(\times 0.0001)$ and are shown as means \pm SEM $(n=3-8) .{ }^{*} p<0.05$, Student's $t$ test

the OZR. Together, the findings suggest that connexin 40associated gap junctions are defective in insulin resistance. Since the mesenteric artery homogenates used for the measurement of protein and mRNA expression contained both endothelial and smooth muscle cells, the data do not allow any conclusions to be drawn concerning the cellular location of the gap junctions.

The use of gap peptides (Gap26 and Gap27) was first characterised by Chaytor and colleagues in 1997 [38]. These peptides contain a motif identical in sequence to a portion of the secondary extracellular loop of the specific connexin it targets, and is thought to interfere with both functional gap junction formation and stability [11]. Gap peptides have been shown to inhibit the hyperpolarisation induced by endothelium-dependent vasodilators in rat mesenteric [39] and saphenous [6] arteries, and inhibit relaxations to acetylcholine in rabbit central ear arteries [40]. Additionally, gap peptides have been shown to abolish gap junctionmediated vasomotion in rat basilar arteries [41]. Studies have also shown that some tissues require a combination of gap peptides to cause significant attenuation of the relaxation response [10], with individual peptides observed to have either no or negligible effects. An important application of this concept was highlighted in a recent study demonstrating that connexin 37 and connexin 40 are involved in the initial propagation of the hyperpolarisation response from the subintimal media layers to the smooth muscle layer, whereas connexin 43 is involved in the further propagation of the electrical stimulus through to the subadventitial layers of the media [16]. It remains to be determined whether these inhibitors affect homocellular coupling or myoendothelial heterocellular coupling, indicating a need to identify the specific connexins that form the heterocellular gap junctions between endothelial cells and smooth muscle cells, or to produce more specific inhibitors against such gap junctions.

The physiological importance of connexin 40 has been identified in a number of studies reporting that a loss of connexin 40 (either through genetic mutation or connexin
40 inhibitors) results in an increase in blood pressure and a loss of vasocontrol $[42,43]$. The inhibition of gap junction communication with connexin-mimetic peptides ${ }^{40} \mathrm{Gap} 27$ or ${ }^{43} \mathrm{Gap} 27$ has been shown to block EDHF-mediated signal transmission in vivo, indicated by the abolition of NAME- and indomethacin-resistant renal vasodilation [43]. The gap peptides were also found to cause a decrease in basal renal blood flow, which possibly contributed to the increase in blood pressure noted in this study [43]. This was one of the first studies to support a role for tonic EDHF release in the control of tissue perfusion and vascular resistance, and to show the importance of gap junctions in the EDHF response. The results of studies conducted using connexin 40-deficient mice have also emphasised the importance of gap junctions, specifically, those associated with connexin 40 , in the normal physiological transmission of endothelium-dependent vasodilation [44]. This set of studies showed that a lack of connexin 40 leads to the development of hypertension, and to irregular vasomotion in resistance arteries [42]. Another important outcome of these studies was the finding that the vessels needed to be locally stimulated with acetylcholine for the attenuated propagation along the endothelium to become apparent. This is in contrast to most studies, including this one, in which responses to acetylcholine are studied in chambers where acetylcholine is administered along the whole vessel, hence disguising any defects in propagation.

While there has been considerable work carried out on the nature of gap junctions under normal physiological conditions, the effect of insulin resistance and diabetes on connexins is less well understood. Gap junction pathways in retinal arteries [45] and gap junction activity in mesenteric arteries [24] from STZ-induced diabetic rats have been shown to be reduced, and Ding et al. [46] demonstrated that $C x 37$ mRNA expression was reduced in small mesenteric arteries from STZ-induced diabetic apoEdeficient mice compared with nondiabetic apoE-deficient control mice. Furthermore, we have shown a decrease in gap junction activity in isolated renal arteries from the female 25-week-old OZRs, associated with decreases in connexin 40 protein levels and $C x 40$ mRNA expression (E. J Young and J. J Reid, unpublished data). Collectively, these data together with the present results suggest that the diabetic state is associated with a reduction in the activity and expression of vascular connexins.

In conclusion, we have demonstrated that EDHF-attributed endothelial dysfunction in OZR mesenteric arteries can be associated with a reduction in connexin 40 protein and $C x 40$ mRNA levels. These data complement the functional data showing that connexin 40-associated gap junctions contribute to EDHF-derived responses to acetylcholine in thirdorder mesenteric arteries from the LZRs, but not the OZRs. 
Acknowledgements This work was funded by a National Heart Foundation of Australia Grant-in-Aid (J. J. Reid), an Edward Dunlop Foundation Grant (J. J. Reid) and a Research Infrastructure Award from RMIT (J. J. Reid, M. A. Hill, C. R. Triggle). W. B. Wiehler was supported by a Canadian Institutes of Health Research (CIHR) Group grant to the Smooth Muscle Research Group, University of Calgary and a Canadian Diabetes Association Grant (C. R. Triggle). The authors acknowledge the technical assistance of W. Lau and M. Hashem.

Duality of interest The authors declare that there is no duality of interest associated with this manuscript.

\section{References}

1. De Vriese AS, Verbeuren TJ, Van de Voorde J, Lameire NH, Vanhoutte PM (2000) Endothelial dysfunction in diabetes. Br J Pharmacol 130:963-974

2. Doughty JM, Plane F, Langton PD (1999) Charybdotoxin and apamin block EDHF in rat mesenteric artery if selectively applied to the endothelium. Am J Physiol 276:H1107-H1112

3. Garland CJ, Plane F (1996) Relative importance of endotheliumderived hyperpolarising factor for the relaxation of vascular smooth muscle in different arterial beds. In: Vanhoutte PM (ed) Endothelium-derived hyperpolarising factor. Harwood Academic Publishers, Amsterdam, pp 173-179

4. Feletou M, Vanhoutte PM (1996) Endothelium-derived hyperpolarizing factor. Clin Exp Pharmacol Physiol 23:1082-1090

5. Eichler I, Wibawa J, Grgic I et al (2003) Selective blockade of endothelial $\mathrm{Ca}^{2+}$-activated small- and intermediate-conductance $\mathrm{K}^{+}$-channels suppresses EDHF-mediated vasodilation. Br J Pharmacol 138:594-601

6. Sandow SL, Goto K, Rummery NM, Hill CE (2004) Developmental changes in myoendothelial gap junction mediated vasodilator activity in the rat saphenous artery. J Physiol 556:875-886

7. McNeish AJ, Garland CJ (2007) Thromboxane A2 inhibition of $\mathrm{SK}_{\mathrm{Ca}}$ after $\mathrm{NO}$ synthase block in rat middle cerebral artery. Br J Pharmacol 151:441-449

8. Crane GJ, Gallagher N, Dora KA, Garland CJ (2003) Small- and intermediate-conductance calcium-activated $\mathrm{K}^{+}$channels provide different facets of endothelium-dependent hyperpolarization in rat mesenteric artery. J Physiol 553:183-189

9. Gluais P, Edwards G, Weston AH, Falck JR, Vanhoutte PM, Feletou M (2005) Role of $\mathrm{SK}_{\mathrm{Ca}}$ and $\mathrm{IK}_{\mathrm{Ca}}$ in endotheliumdependent hyperpolarizations of the guinea-pig isolated carotid artery. Br J Pharmacol 144:477-485

10. Chaytor AT, Martin PE, Edwards DH, Griffith TM (2001) Gap junctional communication underpins EDHF-type relaxations evoked by ACh in the rat hepatic artery. Am J Physiol Heart Circ Physiol 280:H2441-H2450

11. Edwards G, Feletou M, Gardener MJ, Thollon C, Vanhoutte PM, Weston AH (1999) Role of gap junctions in the responses to EDHF in rat and guinea-pig small arteries. $\mathrm{Br} \mathrm{J}$ Pharmacol 128:1788-1794

12. Sokoya EM, Burns AR, Setiawan CT, Coleman HA, Parkington HC, Tare M (2006) Evidence for the involvement of myoendothelial gap junctions in EDHF-mediated relaxation in the rat middle cerebral artery. Am J Physiol Heart Circ Physiol 291: $\mathrm{H} 385-\mathrm{H} 393$

13. Yeager M, Unger VM, Falk MM (1998) Synthesis, assembly and structure of gap junction intercellular channels. Curr Opin Struct Biol 8:517-524
14. Emerson GG, Segal SS (2000) Electrical coupling between endothelial cells and smooth muscle cells in hamster feed arteries: role in vasomotor control. Circ Res 87:474-479

15. de Wit C, Wolfle SE (2007) EDHF and gap junctions: important regulators of vascular tone within the microcirculation. Curr Pharm Biotechnol 8:11-25

16. Chaytor AT, Bakker LM, Edwards DH, Griffith TM (2005) Connexin-mimetic peptides dissociate electrotonic EDHF-type signalling via myoendothelial and smooth muscle gap junctions in the rabbit iliac artery. Br J Pharmacol 144:108-114

17. Miller AW, Katakam PV, Ujhelyi MR (1999) Impaired endothelium-mediated relaxation in coronary arteries from insulinresistant rats. J Vasc Res 36:385-392

18. Miller AW, Hoenig ME, Ujhelyi MR (1998) Mechanisms of impaired endothelial function associated with insulin resistance. J Cardiovasc Pharmacol Ther 3:125-134

19. Coppey LJ, Gellett JS, Yorek MA (2003) Mediation of vascular relaxation in epineurial arterioles of the sciatic nerve: effect of diabetes in type 1 and type 2 diabetic rat models. Endothelium 10:89-94

20. Burnham MP, Johnson IT, Weston AH (2006) Impaired smallconductance $\mathrm{Ca}^{2+}$-activated $\mathrm{K}^{+}$channel-dependent EDHF responses in type II diabetic ZDF rats. Br J Pharmacol 148:434-441

21. Matsumoto T, Kakami M, Noguchi E, Kobayashi T, Kamata K (2007) Imbalance between endothelium-derived relaxing and contracting factors in mesenteric arteries from aged OLETF rats, a model of type 2 diabetes. Am J Physiol Heart Circ Physiol 293: H1480-H1490

22. Kuroki T, Inoguchi T, Umeda F, Ueda F, Nawata H (1998) High glucose induces alteration of gap junction permeability and phosphorylation of connexin-43 in cultured aortic smooth muscle cells. Diabetes 47:931-936

23. Inoguchi T, Yu HY, Imamura M et al (2001) Altered gap junction activity in cardiovascular tissues of diabetes. Med Electron Microsc 34:86-91

24. Wigg SJ, Tare M, Tonta MA, O’Brien RC, Meredith IT, Parkington HC (2001) Comparison of effects of diabetes mellitus on an EDHF-dependent and an EDHF-independent artery. Am J Physiol Heart Circ Physiol 281:H232-H240

25. Matsumoto T, Kobayashi T, Kamata K (2003) Alterations in EDHF-type relaxation and phosphodiesterase activity in mesenteric arteries from diabetic rats. Am J Physiol Heart Circ Physiol 285:H283-H291

26. Kasiske BL, O'Donnell MP, Keane WF (1992) The Zucker rat model of obesity, insulin resistance, hyperlipidemia, and renal injury. Hypertension 19:I110-I115

27. Kuo L, Davis MJ, Chilian WM (1988) Myogenic activity in isolated subepicardial and subendocardial coronary arterioles. Am J Physiol 255:H1558-H1562

28. Hill MA, Ege EA (1994) Active and passive mechanical properties of isolated arterioles from STZ-induced diabetic rats. Effect of aminoguanidine treatment. Diabetes 43:1450-1456

29. Duling BR, Gore RW, Dacey RG Jr, Damon DN (1981) Methods for isolation, cannulation, and in vitro study of single microvessels. Am J Physiol 241:H108-H116

30. Potocnik SJ, Murphy TV, Kotecha N, Hill MA (2000) Effects of mibefradil and nifedipine on arteriolar myogenic responsiveness and intracellular $\mathrm{Ca}^{2+}$. Br J Pharmacol 131:1065-1072

31. McCulloch AI, Randall MD (1996) Modulation of vasorelaxant responses to potassium channel openers by basal nitric oxide in the rat isolated superior mesenteric arterial bed. $\mathrm{Br} \mathrm{J}$ Pharmacol 117:859-866

32. Katakam PV, Ujhelyi MR, Miller AW (1999) EDHF-mediated relaxation is impaired in fructose-fed rats. J Cardiovasc Pharmacol $34: 461-467$ 
33. Nelson MT, Brayden JE (1993) Regulation of arterial tone by calcium-dependent $\mathrm{K}^{+}$channels and ATP-sensitive $\mathrm{K}^{+}$channels. Cardiovasc Drugs Ther 7(Suppl 3):605-610

34. Wulff H, Miller MJ, Hansel W, Grissmer S, Cahalan MD, Chandy KG (2000) Design of a potent and selective inhibitor of the intermediateconductance $\mathrm{Ca}^{2+}$-activated $\mathrm{K}^{+}$channel, IKCa1: a potential immunosuppressant. Proc Natl Acad Sci USA 97:8151-8156

35. Richards GR, Weston AH, Burnham MP, Feletou M, Vanhoutte PM, Edwards G (2001) Suppression of $\mathrm{K}^{+}$-induced hyperpolarization by phenylephrine in rat mesenteric artery: relevance to studies of endothelium-derived hyperpolarizing factor. $\mathrm{Br} \mathrm{J}$ Pharmacol 134:1-5

36. Edwards G, Feletou M, Gardener MJ et al (2001) Further investigations into the endothelium-dependent hyperpolarizing effects of bradykinin and substance $\mathrm{P}$ in porcine coronary artery. Br J Pharmacol 133:1145-1153

37. Chaytor AT, Marsh WL, Hutcheson IR, Griffith TM (2000) Comparison of glycyrrhetinic acid isoforms and carbenoxolone as inhibitors of EDHF-type relaxations mediated via gap junctions. Endothelium 7:265-278

38. Chaytor AT, Evans WH, Griffith TM (1997) Peptides homologous to extracellular loop motifs of connexin 43 reversibly abolish rhythmic contractile activity in rabbit arteries. J Physiol 503:99-110

39. Sandow SL, Tare M, Coleman HA, Hill CE, Parkington HC (2002) Involvement of myoendothelial gap junctions in the actions of endothelium-derived hyperpolarizing factor. Circ Res 90:1108-1113

40. Berman RS, Martin PE, Evans WH, Griffith TM (2002) Relative contributions of $\mathrm{NO}$ and gap junctional communication to endothelium-dependent relaxations of rabbit resistance arteries vary with vessel size. Microvasc Res 63:115-128

41. Haddock RE, Grayson TH, Brackenbury TD et al (2006) Endothelial coordination of cerebral vasomotion via myoendothelial gap junctions containing connexins 37 and 40. Am J Physiol Heart Circ Physiol 291:H2047-H2056

42. de Wit C, Roos F, Bolz SS, Pohl U (2003) Lack of vascular connexin 40 is associated with hypertension and irregular arteriolar vasomotion. Physiol Genomics 13:169-177

43. De Vriese AS, Van de Voorde J, Lameire NH (2002) Effects of connexin-mimetic peptides on nitric oxide synthase- and cyclooxygenase-independent renal vasodilation. Kidney Int 61:177-185

44. de Wit C, Roos F, Bolz SS et al (2000) Impaired conduction of vasodilation along arterioles in connexin40-deficient mice. Circ Res 86:649-655

45. Oku H, Kodama T, Sakagami K, Puro DG (2001) Diabetesinduced disruption of gap junction pathways within the retinal microvasculature. Invest Ophthalmol Vis Sci 42:1915-1920

46. Ding H, Hashem M, Wiehler WB et al (2005) Endothelial dysfunction in the streptozotocin-induced diabetic apoE-deficient mouse. Br J Pharmacol 146:1110-1118 